Journal of Animal and Veterinary Advances 11 (17): 3125-3131, 2012

ISSN: $1680-5593$

(C) Medwell Journals, 2012

\title{
Cloning and Characterization of New Splice Variants of Insulin-Like Growth Factor-1 Gene in Songliao Black Pig
}

\author{
${ }^{1,2}$ Chang Liu, ${ }^{1}$ Zhihui Zhaoa, ${ }^{1,}{ }^{3}$ Wenlin Bai, ${ }^{1}$ Boxing Sun, \\ ${ }^{1}$ Yonghong Zhang and ${ }^{1}$ Runjun Yang \\ ${ }^{1}$ College of Animal Science and Veterinary Medicine, Jilin University, \\ Xi An Road 5333, 130062 Changchun, Jilin, P.R. China \\ ${ }^{2}$ Institute of Animal Science and Veterinary Medicine, \\ Shandong Academy of Agricultural Sciences, 250100 Shandong, China \\ ${ }^{3}$ College of Animal Science and Veterinary Medicine, Shenyang Agricultural University, \\ 110866 Shenyang, Liaoning, China
}

\begin{abstract}
Insulin-Like Growth Factor $1(I G F-1)$ is a single copy gene. It generates several IGF-1 mRNA variants due to alternative splicing. Spliced variants of IGF-1 being some small peptides derived from spliced variants of IGF-1 have critical roles in cell metabolism and growth of various vertebrate species. Porcine $I G F-1$ gene has two promoters and the existence of Exon 6 has been confirmed in Songliao Black pig in the laboratory. The aims of the present study were to identify new spliced variants of $I G F-1$ gene including Exon 5 and to investigate their expression profile in different tissues of Songliao Black pig. The cDNAs of two new spliced variants of $I G F-1$ gene were cloned by RACE. These two variants were named Class I IGF-1-Eb and Class II IGF-1-Eb, respectively. The Class I IGF-1-Eb contains an Open Reading Frame (ORF) of 564 bp encoding 187 amino acids (GenBank Accession No. FJ91 4497). The Class II IGF-1-Eb contains an ORF of 516-bp encoding 171 amino acids (GenBank Accession No. FJ914498). Tissue distributions of mRNAs of Class I IGF-1-Eb and Class II IGF-1-Eb were investigated in Songliao Black pig by semi-quantitative RT-PCR. Both of the new mRNA variants were expressed in a variety of tissues. Class I IGF-1-Eb mRNA was more abundant than Class II IGF-1-Eb mRNA in most tissues except for duodenum and longissimus muscle $(p<0.05)$.
\end{abstract}

Key words: Insulin-Like Growth Factor 1 (IGF-1), alternative splicing, Songliao Black pig, tissues, expression

\section{INTRODUCTION}

Insulin-Like Growth Factor-1 (IGF-1) gene is one of the members of the $I G F S$ gene family which plays an important role in mediating the growth and the molecular metabolism (Cote et al., 2007; Dragisic et al., 2006; Krych et al., 2007; O'Callaghan and O'Connor, 2004; Takahashi et al., 2003). The $I G F-1$ gene of pig was located in the long arm of chromosome 5 (Tang et al., 2002). It consists of at least six exons and five introns spanning a region of $>80 \mathrm{~kb}$ of genomic DNA. Exons 1 and 2 are alternative leader exons with distinct transcription start sites. They encode part of the signal peptide which are spliced differentially to the common Exon 3 and produce Class I and II IGF-1 mRNA transcripts, respectively (Jackson and Sun, 2001; Yaseen et al., 2001). Exons 3 and 4 are constant. Exon 3 encodes the remaining of the signal peptide and the first part of the B domain of the IGF-1 peptide. Exon 4 encodes the remainder of the B, C, A and $\mathrm{D}$ domains as well as the first part of the $\mathrm{E}$ domain (Maile et al., 2008). The remainder of E peptide and $3^{\prime} U T R$ were encoded by alternative usage of Exons 4-6. The amino acid residues encoded by Exons 4 and 6 in the $\mathrm{E}$ domain were named Ea (Ren et al., 2007; Shioura et al., 2006; Yang et al., 2008). The amino acid residues encoded by Exons 4 and 5 in the $E$ domain were named Eb. Multiple forms of pro IGF-1 have been cloned in human (Palsgaard et al., 2009), rat (Chang et al., 2003), sheep (Scata et al., 2010), bovine (Hashemi et al., 2011), pig (Tang et al., 2002), zebra fish (Berishvili et al., 2006), Japanese eel, Nile tilapia and Sparus aurata (Carnevali et al., 2005). All these different forms of IGF-1 are results of the alternative splicing of the region encoding $\mathrm{E}$ domain.

Songliao Black pig is one of the major breeds found in Jilin province of China. It has certain characters such

Corresponding Author: Runjun Yang, College of Animal Science and Veterinary Medicine, Jilin University, Xi An Road 5333, 130062 Changchun, Jilin, P.R. China 
as high reproduction rate, disease resistance and good meat quality, etc. It is important to accelerate the development and improve the growth of this breed. Researchwers EARLIER cloned Class I and Class I IGF-1 mRNAs which were derived by Exon 1 or 2 alternative spliced to Exon 6. The highest levels of IGF-1 mRNAs were observed in the liver and the two classes of IGF-I mRNAs were expressed in all tissues examined. In the present study, researchers cloned two new variants of IGF-II cDNAs from the liver by RACE technique and examined their tissue distribution.

\section{MATERIALS AND METHODS}

Ethics statement: Animal experiments were done in strict accordance with the guide for the care and use of laboratory animals by the Jilin University Animal Care and Use Committee (Permit No: SYXK (Ji) 2008-0010/0011). All surgery was performed under sodium pentobarbital anesthesia and all efforts were made to minimize suffering.

All experimental Songliao Black pigs were obtained from Animal Science Branch of Jilin Academy for Agriculture Science. Tissues analyzed including heart, liver, spleen, lung, kidney, stomach, duodenum, ileum, colon, appendix, brachi-triceps, longissimus muscle and biceps femoris were dissected and immediately frozen in liquid nitrogen after slaughtered and stored at $-80^{\circ} \mathrm{C}$.

Cloning of IGF-I cDNA: Total RNA was isolated from Songliao Black pig liver using TRIzol reagent (Invitrogen, CA, USA) according to the manufacturer's instructions. RNA concentrations were calculated based on the absorbance at $260 \mathrm{~nm}$. RNA quality was confirmed by denaturing agarose gel electrophoresis.

The 3'-RACE were performed to amplify the 3'-end of Songliao Black pig IGF-1 cDNA using a 3'-Full RACE Core Set Ver., 2.0 kit (TaKaRa, Dalian, China). First, the 3' end-cDNA was synthesized from $1.0 \mu \mathrm{g}$ of total RNA from liver using the 3'-RACE adaptor from the kit and the reverse transcript was performed based on the earlier cloned sequence of IGF-1 by Xiao et al. (2009) (Genbank Accession No: DQ784687). First PCR conditions consisted of denaturing at $94^{\circ} \mathrm{C}$ for $2 \mathrm{~min}$ followed by 25 cycles of $30 \mathrm{sec}$ at $94^{\circ} \mathrm{C}, 15 \mathrm{sec}$ at $58^{\circ} \mathrm{C}$ and $1 \mathrm{~min}$ at $72^{\circ} \mathrm{C}$. Second PCR conditions consisted of denaturing at $95^{\circ} \mathrm{C}$ for $3 \mathrm{~min}$ followed by 25 cycles of $30 \mathrm{sec}$ at $94^{\circ} \mathrm{C}$, $30 \mathrm{sec}$ at $58^{\circ} \mathrm{C}$ and $1 \mathrm{~min} 40 \mathrm{sec}$ at $72^{\circ} \mathrm{C}$. The amplification of the target cDNAs was carried out using a hot start and touchdown PCR with a nested PCR. Table 1 show the forward and reverse primer sequences used in the 3'-RACE experiment. Primers were designed using the Oligo Ver., 6.0 Software. Reverse primer, 3'-RACE Outer Primer and 3'-RACE Inner Primer were supplied by the 3'-Full RACE Core Set Ver., 2.0 kit.

The products of the nested PCR were purified using the SUPRECTM-02 kits and cloned into $\mathrm{pMD}-18 \mathrm{~T}$ vector according to the manufacture's instructions. The sequence of the cDNA inserted was determined by sequencing (Shanghai Sangon, China). Sequence analysis was carried out using the blast program (http://www.ncbi.nlm.nih.gov/).

RT-PCR for IGF-1 Eb mRNA expression: Tissue distribution of Class I IGF-1-Eb and Class II IGF-1-Eb mRNAs in Songliao Black pig was investigated by semi-quantitative RT-PCR. Total RNA were extracted from heart, liver, spleen, lung, kidney, stomach, duodenum, ileum, colon, appendix, brachi-triceps, longissimus muscle of back and biceps femoris of 6 months old Songliao Black pig using TRIzol Reagent (Invitrogen, CA, USA) according to the manufacturer's instruction. First-strand cDNAs were reverse -transcribed from total RNA $(1 \mu \mathrm{g})$ using oligo (dT) 18 primers and Avian Myeloblastosis Virus Reverse Transcriptase (AMVRT, Promega, USA) according to the manufacture's instruction.

An amplified fragment of $\beta$-actin was used as a standard. For the detection of gene transcripts, $50 \mu \mathrm{L}$ of reaction mix, $5 \mu \mathrm{L} 10 \times \mathrm{PCR}$ buffer, $4 \mu \mathrm{L}$ dNTP Mix $\left(2.5 \mathrm{mmol} \mathrm{L}^{-1}\right), 1 \mu \mathrm{L}$ each primer set $(10 \mu \mathrm{M}), 1 \mu \mathrm{L}$ cDNA template, $0.5 \mu \mathrm{L}$ Taq DNA Polymerase $(5 \mathrm{U} \mu \mathrm{L}), 37.5 \mu \mathrm{L}$ sterile distilled water were mixed on ice. PCR conditions were optimized by first checking the linearity ( $25-40$ cycles at different annealing temperatures between $50-60^{\circ} \mathrm{C}$ ). Thermal cycling conditions were as follows: initial activation at $95^{\circ} \mathrm{C}$ for $3 \mathrm{~min}, 30$ cycles of $94^{\circ} \mathrm{C}$ for $30 \mathrm{sec}$, $56-60^{\circ} \mathrm{C}$ for $30 \mathrm{sec}, 72^{\circ} \mathrm{C}$ for $40 \mathrm{sec}$ and a final extension at $72^{\circ} \mathrm{C}$ for $10 \mathrm{~min}$. PCR products were loaded into a gel ( $2 \%$ agarose) and stained with ethidium bromide and photographed under ultraviolet rays. The products were quantified by use of a Band Scan. Values for IGF-1 were normalized with the values for $\beta$-actin.

Table 1: Forward and reverse primer sequences used for 3 '-RACE

\begin{tabular}{lll}
\hline Primers & Sequences & \\
\hline Forward GSP1 & 5'-TGGTGGACGCTCTTCAGTTC-3' & Bases (bp) \\
3'-RACE outer primer & 5'-TACCGTCGTTCCACTAGTGATTT-3' \\
Forward GSP2 & 5'-ATCGTGGATGAGTGCTGCTTC-3' \\
3'-RACE inner primer & 5'-CGCGGATCCTCCACTAGTGATTTCACTATAGG-3' & 23 \\
\hline
\end{tabular}


Table 2: Primers used for RT-PCR

\begin{tabular}{llc}
\hline Genes & Primers & Temrature $\left({ }^{\circ} \mathrm{C}\right)$ \\
\hline Class I $I G F-I-E b$ & F:ATCAGCAGTCTTCCAACCCAA & 58 \\
& R:CTCCTGGGTGTTCTTTGG & \\
Class II $I G F-I-E b$ & F:CCACCCTGACCTGCTGTAAAAG & 60 \\
& R:CTCCTGGGTGTTTCTTGG & \\
$\beta$-actin & F:GAGAAGCTCTGCTACGTCGC & 58 \\
& R:CCAGACAGCACCGTGTTGGC c & \\
\hline
\end{tabular}

According to the mRNA sequences of Class I IGF-1-Eb and Class II IGF-1-Eb of Songliao Black pig deposited in GenBank (Accession No: FJ914497 and FJ914498) and $\beta$-actin gene (Genbank Accession No, DQ845171), primers for semi-quantitative RT-PCR were designed using the Oligo Ver., 6.0 Software (Table 2).

Statistical analyses: Results were indicated as mean \pm SEM. Data were analyzed using one-way Analysis of Variance (ANOVA). The Least Significant Difference test was used to determine significant differences between means. All statistical analyses were done using SPSS 12.0 Software.

\section{RESULTS AND DISCUSSION}

IGF-I mRNA transcripts in Songliao Black pig tissue: The cDNA sequences of two spliced variants of $I G F-1$ gene in Songliao Black pig including Exon 5 were cloned by RACE-PCR. They were named Class I IGF-1-Eb (Genbank Accession No. FJ914497) and ClassII IGF-1Eb (Genbank Accession No. FJ914498). The Class I IGF-1-Eb cDNA consisted of 1133 bp containing a 5' UTR of $246 \mathrm{bp}$ an open reading frame of $564 \mathrm{bp}$ and a $3^{\prime}$ UTR of $323 \mathrm{bp}$.

The open reading frame encoded 187 amino acids. The deduced amino acids of Class I IGF-1-Eb included a signal peptide of 48 amino acids, an $\mathrm{E}$ domain of 69 amino acids and a mature protein of 70 amino acids containing a B domain (29 aa), C domain (12 aa), A domain (21aa) and a $\mathrm{D}$ domain ( $8 \mathrm{aa}$ ).

The six conserved cysteine residues were found in the domains $\mathrm{B}$ and $\mathrm{A}$ of the mature peptide (CysB6, CysB18, CysA6, CysA7, CysA11 and CysA20) (Fig. 1a). Whereas the cDNA of Class II IGF-1-Eb was 914 bp in length containing a $5^{\prime}$-UTR of $75 \mathrm{bp}$, an open reading frame of $516 \mathrm{bp}$ and a $3^{\prime}$-UTR of $323 \mathrm{bp}$. The open reading frame encoded 171 amino acids containing the signal peptide (32 aa) and the pro-IGF-1 (139 aa). The five structural domains ( $\mathrm{B}, \mathrm{C}, \mathrm{A}, \mathrm{D}$ and $\mathrm{E})$ and six conserved cysteine residues have the same sequences of the Class II IGF-1-Eb (Fig. 1b).

Comparisons of amino acid sequence of Class I IGF-1-Eb and Class II IGF-1-Eb between Songliao Black pig and other animals revealed a high sequence identity (Table 3 and 4). The amino acid sequence of Class I IGF-1-Eb has identity of 79.9-93.4\% with that of mammalians analyzed, identity of $71.1 \%$ with that of frog and identity $62.1 \%$ with that of fish whereas Class II IGF-1-Eb has identity of 77.3-94\% with that of mammalians analyzed (Fig. 2).

The amino acid sequence of Class I IGF-1-Eb has identity of $79.9-93.4 \%$ with that of mammalians analyzed, identity of $71.1 \%$ with that of frog and identity $62.1 \%$ with that of fish whereas Class II IGF-1-Eb has identity of $77.3-94 \%$ with that of mammalians analyzed (Table 3 ).

The predicted mature peptide of IGF-1-Eb has the following homologies with other IGF-1 s: Class I IGF-1-Eb having identity of $100 \%$ with chimpanzee, human, panda and $\operatorname{dog}, 95.7 \%$ with rat, $94.3 \%$ with mouse and marmoset, $85.7 \%$ with frog and $82.9 \%$ with fish. Whereas Class II IGF-1-Eb has identity of $100 \%$ with chimpanzee, human and panda, $98.6 \%$ with rabbit, $95.7 \%$ with rat and $94.3 \%$ with marmoset.

Domains B and A of Class I and Class II IGF-1-Eb exhibited the highest sequence conservation compared with other animals. On the other hand, the $\mathrm{E}$ domain of Class I IGF-1-Eb has identity of $59-88.4 \%$ with that of mammalians, $58.6 \%$ with that of African clawed frog and $43.9 \%$ with that of fish whereas the E domain of Class II IGF-1-Eb has identity of $64.4-88.4 \%$ with that of mammalians (Table 4).

Tissue expression distribution of IGF-1 alternatively spliced transcripts in Songliao Black pig: The tissue distribution and relative transcription levels of Class I IGF-1-Eb and Class IIIGF-1-Eb were measured by RT-PCR in heart, liver, spleen, lung, kidney, stomach, duodenum, jejunal, ileum, colon, appendix, brachi-triceps, longissimus muscle of back and biceps femoris from 6 months old Songliao Black pig.

The results indicate that both alternatively spliced transcripts were expressed in all tissues examined. The highest and the lowest Class I IGF-1-Eb mRNA levels were observed in the heart and spleen, respectively and relatively high levels in the ileum, brachi-triceps and biceps femoris (Fig. 2a). The highest and the lowest Class II IGF-1-Eb mRNA levels were observed in the biceps femoris and spleen, respectively and relatively high levels in duodenum and longissimus muscle of back as well as, relatively low levels in the liver and spleen (Fig. 2b). In all tissue (except for duodenum and longissimus muscle) the Class I IGF-1-Eb mRNA levels were more abundant than Class I IGF-1-Eb mRNA levels $(\mathrm{p}<0.05)$ (Fig. 3). 
Table 3: Comparison of the predicted amino acid sequence of Class I IGF-1-Eb between Songliao Black pig and other animals AA sequence identifies $(\%)$

\begin{tabular}{|c|c|c|c|c|c|c|c|c|}
\hline \multirow[b]{3}{*}{ Class I Eb/species } & & & & & & & & \\
\hline & \multirow[b]{2}{*}{ Whole protein } & \multirow[b]{2}{*}{ Signal peptide } & \multirow[b]{2}{*}{ Mature peptide } & \multicolumn{5}{|c|}{ Domain } \\
\hline & & & & B & $\mathrm{C}$ & $\mathrm{A}$ & $\mathrm{D}$ & $\mathrm{E}$ \\
\hline Class I Eb/chimpanzee & 91.4 & 95.8 & 1000.0 & 100.0 & 100.0 & 100.0 & 100.0 & 79.7 \\
\hline Class I Eb/human & 90.9 & 95.8 & 100.0 & 100.0 & 100.0 & 100.0 & 100.0 & 78.3 \\
\hline Class I Eb/panda & 92.9 & 83.3 & 100.0 & 100.0 & 100.0 & 100.0 & 100.0 & 88.4 \\
\hline Class I Eb/dog & 93.4 & 89.6 & 100.0 & 100.0 & 100.0 & 100.0 & 100.0 & 85.3 \\
\hline Class I Eb/rat & 83.1 & 87.5 & 95.7 & 96.6 & 91.7 & 100.0 & 87.5 & 64.4 \\
\hline Class I Eb/mouse & 79.9 & 85.4 & 94.3 & 96.6 & 91.7 & 100.0 & 75.0 & 59.0 \\
\hline Class I Eb/marmoset & 87.7 & 93.8 & 94.3 & 96.6 & 91.7 & 95.2 & 87.5 & 76.8 \\
\hline Class I Eb/frog & 71.1 & 58.3 & 85.7 & 96.6 & 58.3 & 90.5 & 87.5 & 58.6 \\
\hline Class I Eb/fish & 62.1 & 46.9 & 82.9 & 93.1 & 66.7 & 85.7 & 62.5 & 43.9 \\
\hline
\end{tabular}

Pan troglodytes (chimpanzee; GeneBank Accession No. XP 001156459), Homo sapiens (human; GeneBank Accession No. NP 001104755), Callithrix jacchus (marmoset; GeneBank Accession No. XP_002752957), Ailuropoda melonoleuca (panda; GeneBank Accession No. EFB13444), Mus musculus (mouse; GeneBank Accession No. EDL21459), Canis familiaris (dog; GeneBank accession no. XP_866946), Rottus norvegicus (rat; GeneBank accession no. AAA41214), Xenopus leevis (frog; GeneBank Accession No. NP_001156865) and Acipenser ruthenus (fish; GeneBank Accession No. ABC54785)

Table 4: Comparisons of the predicted amino acid sequence of Class II IGF-1-Eb between Songliao Black pig and other animals AA sequence identifies (\%)

Domain

\begin{tabular}{|c|c|c|c|c|c|c|c|c|}
\hline \multirow[b]{2}{*}{ Class II Eb/species } & \multirow[b]{2}{*}{ Whole protein } & \multirow[b]{2}{*}{ Signal peptide } & \multirow[b]{2}{*}{ Mature peptide } & & & & & \\
\hline & & & & $\mathrm{B}$ & $\mathrm{C}$ & A & $\mathrm{D}$ & $\mathrm{E}$ \\
\hline Class II Eb/chimpanzee & 90.4 & 88.9 & 100.0 & 100.0 & 100.0 & 100.0 & 100.0 & 81.2 \\
\hline Class II Eb/human & 89.2 & 88.9 & 100.0 & 100.0 & 100.0 & 100.0 & 100.0 & 79.7 \\
\hline Class II Eb/panda & 94.0 & 92.6 & 100.0 & 100.0 & 100.0 & 100.0 & 100.0 & 88.4 \\
\hline Class II Eb/rabbit & 93.4 & 75.0 & 98.6 & 100.0 & 100.0 & 100.0 & 87.5 & 88.2 \\
\hline Class II Eb/rat & 82.1 & 85.2 & 95.7 & 96.6 & 91.7 & 100.0 & 87.5 & 64.4 \\
\hline Class II Eb/marmoset & 86.1 & 81.5 & 94.3 & 96.6 & 91.7 & 95.2 & 87.5 & 76.8 \\
\hline Class II Eb/mouse & 77.3 & 75.0 & 94.3 & 96.6 & 91.7 & 100.0 & 75.0 & 59.0 \\
\hline
\end{tabular}

Pan troglodytes (chimpanzee; GeneBank Accession No. XP_001156459), Homo sqpiens (human; GeneBank Accession No. NP_001104755), Callithrix jacchus (marmoset; GeneBank Accession No. XP 002752957), Ailuropoda melanole uca (panda; GeneBank Accession No. EFB13444), Mus musculus (mouse; GeneBank Accession No. NP_908941), Oryctolagus cuniculus (rabbit; GeneBank Accession No. NP_001075495), Rattus norvegicus (rat; GeneBank Accession No. AAA41214)

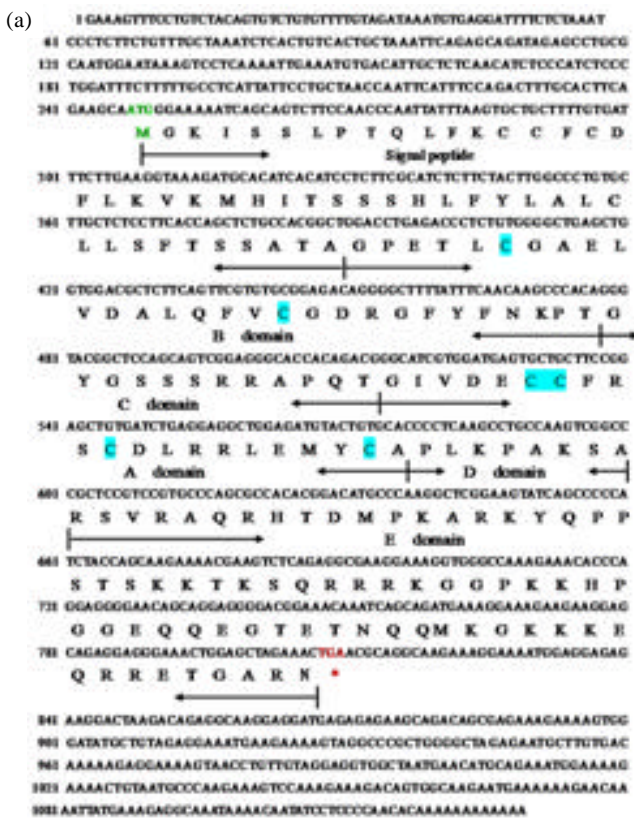

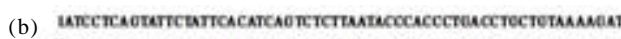

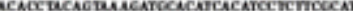
M V T P T V R M B I TS S S B $\stackrel{M}{\longmapsto}$

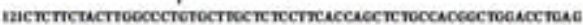
LF Y L A L. C L L S F T S S A TA G P E siged pove

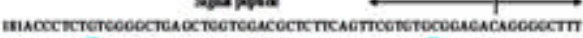

T L. C G A L V D A L Q F V C G D R G F B dimin

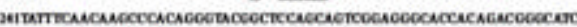

Y F N K P T G Y G S S S R R A P Q T $\stackrel{+}{\longleftrightarrow} \mathrm{C}$ demis V DEC C F R S E D L R R L E $X Y$ E A P A demin

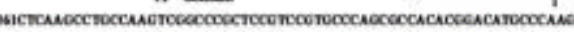
L K P A K S A R S V R A Q R B T D M P K $D$ donia $\longleftrightarrow$ |

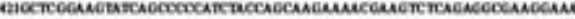
$A R$ K Y Q P P S T S K K T K S Q R R R R

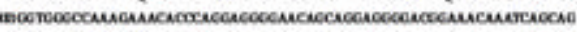

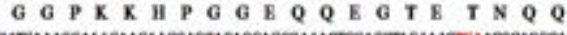

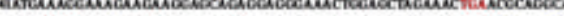
M K G K K K E Q R R E T G A R N *

$$
\text { E domain }
$$

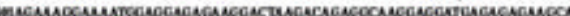

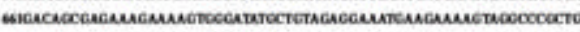

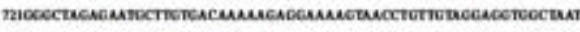

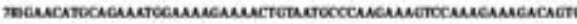
neюсн sucuererumer

Fig. 1: a) Nucleotide and deduced amino acid sequence of Class I preproIGF-I-Eb and b) Class II preproIGF-I-Eb in Songliao Black pig. The signal peptide and the five structural domains ( $B, C, A, D$ and $E$ ) are indicated below the amino acids with the respective nucleotide ranges in arrows. The six conserved cysteine residues are shaded 


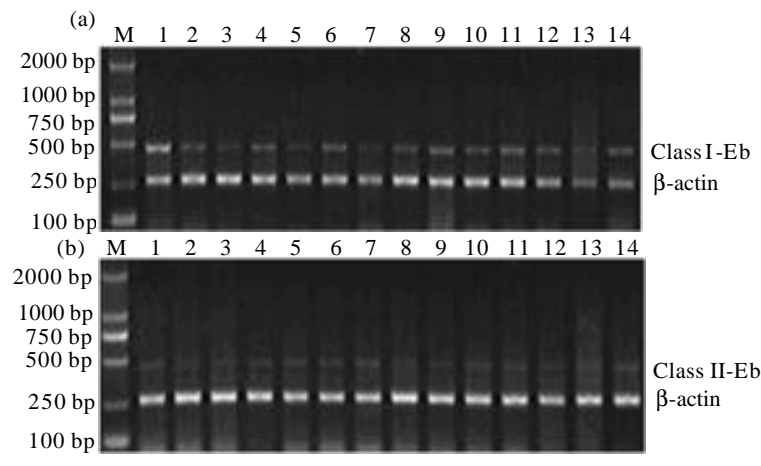

Fig. 2: The electrophoresis pattern of Class I IGF-IEb and Class II IGF-IIEb in different tissues of Songliao Black pig. 1: heart; 2: liver; 3: spleen; 4: lung; 5: kidney; 6: stomach; 7: duodenum; 8: jejuna; 9: ileum; 10: colon; 11: appendix; 12: brachi-triceps; 13: longissimus muscle; 14: biceps femoris

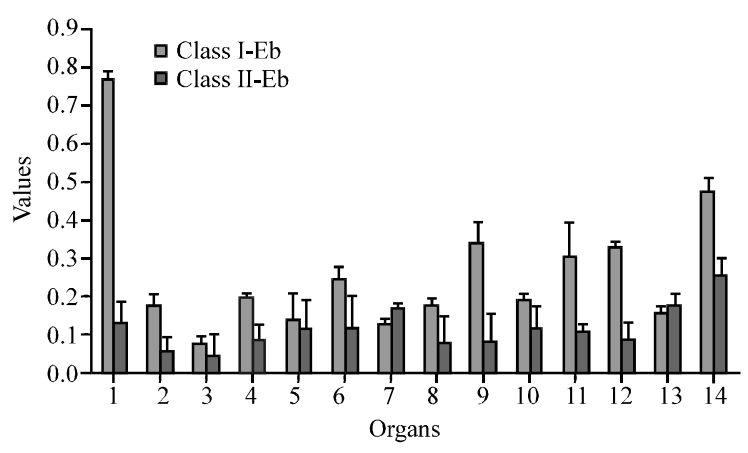

Fig. 3: Expression comparison of $I G F-I I$ gene splice variants in the same tissue from Songliao Black pig. 1: heart; 2: liver; 3: spleen; 4: lung; 5: kidney; 6: stomach; 7: duodenum; 8: jejuna; 9: ileum; 10: colon; 11: appendix; 12: brachi-triceps; 13: longissimus muscle; 14 : biceps femoris

It is well known that alternative splicing is a widely used pattern in higher eukaryotes to regulate gene expression and functional diversification of proteins. To date different mRNA variants of IGF-1 are confirmed in human, rat, sheep, bovine, pig and fish (Ohtsuki et al., 2007, 2005). In this study, two new forms of full length cDNA sequences of IGF-1 have been cloned and their tissue distribution were investigated by semi-quantity RT-PCR. Sequence comparison among the other species indicates that Class I IGF-1-Eb consists of a 48 aa signal peptide, a 70 aa mature peptide and an $E$ domain of 69 aa whereas Class II IGF-1-Eb consists of 32 aa signal peptide, a 70 aa mature peptide and an $\mathrm{E}$ domain of 69 aa. The signal peptides of Class I IGF-1-Eb and Class $\amalg$ n IGF-1-Eb showed very low sequence homology at the sequences of nucleotide and deduced amino acid while the mature peptides and $\mathrm{E}$ domain had the same sequence at both the nucleotide and the deduced amino acid. The most conserved amino acid residues are founded in the B and A domains while considerably less conserved is observed in the C and D domains (Imai et al., 2000; Shand et al., 2003). The six conserved cysteine residues were found in the $\mathrm{B}$ and A domains of the mature peptide (CysB6, CysB18, CysA6, CysA7, CysA11 and CysA20). These cysteines are conserved in the genome and are involved in the binding with their receptors. IGF-binding proteins were conformed in mammals (Duval et al., 2002).

Two types of transcriptons with different 5 ends were detected in Songliao Black pig liver, the result of 3'-RACE suggested that different transcription start sites were used in Exon 1 and 2, respectively. In the experiment of 3'-RACE not only the form of 3 ' end were found with alternative splicing of Exon 3, 4 and 6 but also Exon 3-5 (complete) splicing form in pig liver. And Exon 5 is an alternatively spliced cassette exon of 52 base pairs (bp). Alternative splicing of IGF-1 mRNA results in the synthesis of various types of IGF-1 mRNA in humans, rats and mice (Berishvili et al., 2006). That suggested that maybe there are other splicing form with Exon 5 (only $52 \mathrm{bp}$ ) in some tissues and the function of these IGF-1 moleculars still need to be studied.

In Songliao Black pig, both Class I IGF-1-Eb and Class II IGF-1-Eb mRNAs are expressed in all tissues with varying levels which is consistent with the reported results in other species (Clay et al., 2005; Patruno et al., 2006; Sciara et al., 2008). The highest Class I IGF-1-Eb and Class II IGF-1-Eb mRNA levels in Songliao black pig were observed in the heart. However, there are somewhat difference from that of human, rat, sheep, bovine in which IGF-1 mRNAs levels were deteced in the liver. The expression patterns of both IGF-1 mRNAs in pig are very similar to the other species in which the expression level of Class I IGF-1-Eb mRNA is higher than that of Class II IGF-1-Eb mRNA in most tissues except for duodenum and longissimus muscle.

\section{CONCLUSION}

These results indicate that $I G F-\alpha$ gene is transcribed as Class I IGF-1-Eb and Class II IGF-1-Eb in Songliao Black pig and that the two classes of IGF- $\alpha$ mRNAs were expressed in all tissues examined.

\section{ACKNOWLEDGEMENTS}

Researchers thank Animal Science Branch of Jilin Academy for Agriculture Science for providing the biological material. This research was supported by 
National Natural Science Foundation of China (No.30771543 and 31000991) and Major Project of Chinese National Programs for Fundamental Research and Development (973 program) (No. 2011 CBA01000). Chang Liu and Zhihui Zhaoa contributed equally to this research.

\section{REFERENCES}

Berishvili, G., N. Shved, E. Eppler, F. Clota, J.F. Baroiller and M. Reinecke, 2006. Organ-specific expression of IGF-I during early development of bony fish as revealed in the tilapia, Oreochromis niloticus, by in situ hybridization and immunohistochemistry: indication for the particular importance of local IGF-I. Cell Tissue Res., 325: 287-301.

Carnevali, O., M. Cardinali, F. Maradonna, M. Parisi and I. Olivotto et al., 2005. Hormonal regulation of hepatic IGF-I and IGF-II gene expression in the marine teleost Sparus aurata. Mole. Reprod. Dev., 71: 12-18.

Chang, W.Z., C.H. Ji, M. Centrella and T.L. McCarthy, 2003. Activation domains of CCAAT enhancer binding protein delta: Regions required for native activity and prostaglandin E2-dependent transactivation of IGF-I gene expression in rat osteoblasts. Mole. Endocrinol., 17: 1834-1843.

Clay, L.A., S.Y. Wang, W.R. Wolters, B.C. Peterson and G.C. Waldbieser, 2005. Molecular characterization of the insulin-like growth factor-I (IGF-I) gene in channel catfish (Ictalurus punctatus). Biochim. Biophys. Acta, 1731: 139-148.

Cote, G., G. Perry, P. Blier and L. Bernatchez, 2007. The influence of gene-environment interactions on GHR and IGF-I expression and their association with growth in brook charr, Salvelinus fontinalis (Mitchill). BMC Genet., 8: 87-87.

Dragisic, K., H.C. Liu, Z.Y. He, S. Witkin, Z. Rosenwaks and S. Spandorfer, 2006. Association of IGF-I, IGF-II and IGFBP-3 with individual oocyte maturity in PCOS patients: Evaluation of follicular fluid protein and granulosa cell gene expression. Fertil. Steril., 86: S456-S456.

Duval, H., K. Rousseau, G. Elies, P.Y. Le Bail, S. Dufour, G. Boeuf and D. Boujard, 2002. Cloning, characterization, and comparative activity of turbot IGF-I and IGF-II. Gen. Comp. Endocrinol., 126: $269-278$.

Hashemi, E., M. Daliri, M. Eskandarinasab, M. Dashtizad and A. Zomorodipour, 2011. Analysis of IGF-I and IGF-II gene expression in bovine oviduct cells using real-time PCR. Reprod. Domes. Anim., 46: 73-73.
Imai, Y., A. Moralez, U. Andag, J.B. Clarke, W.H. Busby and D.R. Clemmons, 2000. Substitutions for hydrophobic amino acids in the N-terminal domains of IGFBP-3 and -5 markedly reduce IGF-I binding and alter their biologic actions. J. Biol. Chem., 275: 18188-18194.

Jackson, R.D. and J. Sun, 2001. The regulation of multiple insulin-like growth factor-I transcripts by exogenous IGF-I in human primary bone cells. J. Bone Miner. Res., 16: S479-S479.

Krych, K., H. Mizgajska-Wiktor and A. GozdzickaJozefiak, 2007. Polymorphism in the promoter regions of IGF I gene in elite athletes of different sport disciplines. Febs J., 274: 284-284.

Maile, L.A., B.E. Capps, E.C. Miller, A.W. Aday and D.F. Clemmons, 2008. Integrin-associated protein association with SRC homology 2 domain containing tyrosine phosphatase substrate 1 regulates IGF-I signaling in vivo. Diabetes, 57: 2637-2643.

O'Callaghan, K.M. and R. O'Connor, 2004. Characterisation of an IGF-I responsive gene that encodes a new endosomal protein. Mole. Biol. Cell, 15: $322 \mathrm{a}-322 \mathrm{a}$.

Ohtsuki, T., M. Otsuki, Y. Murakami, K. Hirata, S. Takeuchi and S. Takahashi, 2007. Alternative leader-exon usage in mouse IGF-I mRNA variants: class 1 and class 2 IGF-I mRNAs. Zoolo. Sci., 24: $241-247$.

Ohtsuki, T., M. Otsuki, Y. Murakami, T. Maekawa and T. Yamamoto et al., 2005. Organ-specific and agedependent expression of insulin-like growth factor-I (IGF-I) mRNA variants: IGF-IA and $\mathbb{B}$ mRNAs in the mouse. Zoolog. Sci., 22: 1011-1021.

Palsgaard, J., A.E. Brown, M. Jensen, R. Borup, M. Walker, P. De Meyts, 2009. Insulin-like growth factor I (IGF-I) is a more potent regulator of gene expression than insulin in primary human myoblasts and myotubes. Growth Horm. IGF Res., 19: 168-178.

Patruno, M., L. Maccatrozzo, B. Funkenstein and G. Radaelli, 2006. Cloning and expression of insulin-like growth factors I and II in the shi drum (Umbrina cirrosa). Comp. Biochem. Physiol., 144: 137-151.

Ren, M., Q.B. Guan, X. Zhong, B.D. Gong and $\mathrm{Y}$. Sun et al., 2007. Phosphatidylinositol 3kinase/nuclear factor-kappa B signaling pathway is involved in the regulation of IGF-I on Fasassociated death domain-like interleukin-1-converting enzyme-inhibitory protein expression in cultured FRTL thyroid cells. J. Mole. Endocrinol, 38: $619-625$. 
Scata, M.C., G. Catillo, G. Annicchiarico, G. De Matteis, F. Napolitano, F. Signorelli and B. Moioli., 2010. Investigation on lactation persistency and IGF-I gene polymorphisms in dairy sheep. Small Ruminant Res., 89: 7-11.

Sciara, A.A., G.M. Somoza and S.E. Arranz, 2008. Insulin-like growth factor-I of pejerrey, Odontesthes bonariensis: cDNA characterization, tissue distribution and expression profiles after growth hormone administration. J. Exp. Zoolog., 309: 407-418.

Shand, J.H., J. Beattie, H. Song, K. Phillips, S.M. Kelly, D.J. Flint and G.J. Allan, 2003. Specific amino acid substitutions determine the differential contribution of the $\mathrm{N}$ - and C-terminal domains of insulin-like growth factor (IGF)-binding protein-5 in binding IGF-I. J. Biolog. Chem., 278: 17859-17866.

Shioura, K.M., T. Los, D.L. Geenen, G. Goldspink and P. Goldspink, 2006. The unique E-domain of an IGF-I isoform expressed in muscle preserves cardiac function and prevents apoptosis following myocardial infarction. Circulation, 114: 232-232.

Takahashi, T., K. Ishida, K. Itoh, Y. Konishi and K.I. Yagyu et al., 2003. IGF-I gene transfer by electroporation promotes regeneration in a muscle injury model. Gen. Therap., 10: 612-620.
Tang, M., A.G. Van Kessel and B. Laarveld, 2002. Effects of weaning and rearing environment on intestinal gene expression of IGF-I, IGFBP (1-6) and the IGF receptor and on specific binding of IGF-I to mucosal membranes in the pig. Gen. Comp. Endocrinol., 128: 205-213.

Xiao, S., S. Li, J. Zhang, S. Zhang and L. Dai et al., 2009. Cloning and characterization of class 1 and class 2 insulin-like growth factor-I mRNA in Songliao black pig. Mol. Biol. Rep., 36: 415-421.

Yang, S.Y., K.M. Sales, B.J. Fuller, A.M. Seifalian and M.C. Winslet, 2008. Inducing apoptosis of human colon cancer cells by an IGF-I $\mathrm{D}$ domain analogue peptide. Mol. Cancer, 7: 17-17.

Yaseen, M.A C. Wrenzycki, D. Herrmann, J.W. Carnwath and $\mathrm{H}$. Niemann, 2001. Changes in the relative abundance of mRNA transcripts for insulin-like growth factor (IGF-I and IGF-II) ligands and their receptors (IGF-IR/IGF-IIR) in preimplantation bovine embryos derived from different in vitro systems. Reprod., 122: 601-610. 